\title{
The power of the tiniest shoot
}

\author{
The publication of a white paper on nanoscience in China sets the scene for the country's future \\ in the field.
}

The National Natural Science Foundation of China (NSFC) disclosed that China invested US $\$ 4$ billion in research in 2016. According to their plan, this will be increased to US $\$ 6$ billion in 2020, which is about $2.5 \%$ of China's GDP. This would put China well on track to become the leader of science and innovation by 2050 , in line with the government target. About nanoscience and nanotechnology specifically, the Chinese Academy of Sciences, in collaboration with Springer Nature, has just published a white paper. According to the document, China's contribution to the world's nanoscience papers has been growing for the past two decades and at present is over a third of the total. Furthermore, the quality of the research keeps improving: for the past decade the share of publications in the top $1 \%$ most-cited nanoscience papers with authors from Chinese affiliations has grown at an annual rate of $22 \%$, and has overtaken that from authors with US affiliations. The main topics in which Chinese researchers contribute are catalysis and nanomedicine, but with rising political awareness of the importance of renewable energy, China's efforts are also growing fast in energy harvesting and storage.

Increasing investments also mean more career opportunities for talented researchers who moved to the US or Europe to study or train, but are now returning to China to take important roles and make an impact in their home country. The present statistics suggest that the level of China's international collaboration in nanoscience papers is still much lower, and growing less quickly, than that of the US, France and Germany. But this is bound to change with the continuous increase of the number of returnees, as well as China's rising research activities in nanoscience and nanotechnology. In the past, Chinese researchers needed international collaboration because of the more advanced skills in the US or Europe. Already now, however, the drive is shifting towards the need for different expertise, and collaborations are established more for mutual development. All the local Chinese researchers interviewed for the whtie paper were quite optimistic on this point. According to them, the Chinese government greatly encourages international collaboration and provides many funding programs. Moreover, their PhDs and postdocs are very often supported by international collaboration programmes from research institutes, universities and the Ministry of Education, allowing them to attend international conferences or participate in exchange programmes overseas.

One aspect that should be improved is the incentive to establish collaboration among scientists with different backgrounds in the physical and life sciences, which is essential in nanoscience and nanotechnology. According to many of the researchers interviewed, most sponsorship from common funding bodies is focused on conventional disciplines; there are some special funding programs focused on nanoscience, but their scopes are very limited and usually unable to meet the needs of the diversified nanoscience and nanotechnology community. Aside from the demand for more cross-disciplinary funding, carrying out interdisciplinary collaboration also requires researchers with different backgrounds to be capable of understanding each other. It may be useful for the NSFC to establish more cross-field forums to facilitate the conversations among scientists and engineers coming from different disciplines.

\section{One aspect that should be improved is the incentive for collaboration among scientists with different backgrounds.}

From the white paper it emerges that Chinese researchers in nanoscience and nanotechnology are particularly keen to file their work into patents. The number of patent applications from Chinese researchers increased from 2,826 in 1997 to 51,389 in 2015, and most patents are filed within China. These data imply that China favours applied research in nanoscience. This is confirmed by publication statistics, which say that China publishes much more applied research papers than other countries, with $86.7 \%$ of its papers citing at least one application. Still, most of the researchers interviewed for the white paper believe that even more effort should be put into

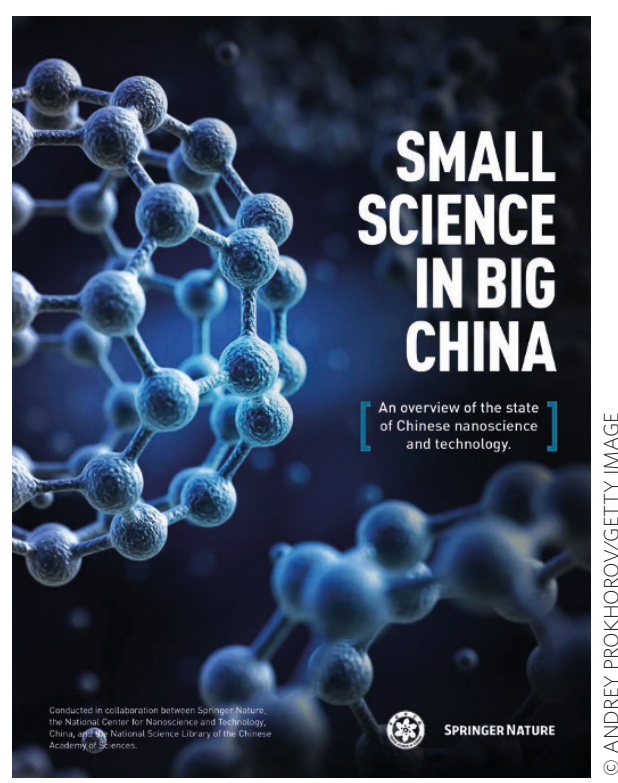

The front cover of the white paper on nanoscience and nanotechnology in China.

applications. This view could be interpreted as a general feeling that, despite the already strong focus on applied research, little of this research can eventually be translated into technology. A few steps in this direction have already been taken - for example, in 2007 the government founded the China Industry-University-Research Institute Collaboration Association to boost the industrialization of laboratory achievements and encourage collaboration between academia and industry - but more has to be done before the effects can be appreciated.

Overall, a positive feature of the white paper is that it also reports the views of scientists rather than just conveying the intention of the government and funding bodies. Eventually, for these scientists, giving importance to their views is the essential aspect that needs improving in the future. They are not too worried about the harsh competition for funding, but in their interviews they emphasized the importance of soft environments, including the attitude to research, the relationship among researchers and so on. They feel that scientists, especially young scientists, should be given more say and should be encouraged to bring up new creative ideas and suggestions. 